\title{
Prospective study of complications of first trimester medical termination of pregnancy at tertiary care center
}

\author{
Radha Rastogi, Bharat Tailor* \\ Department of Obstetrics and Gynecology, RNT Medical College, Udaipur, Rajasthan, India \\ Received: 07 April 2020 \\ Accepted: 05 May 2020 \\ *Correspondence: \\ Dr. Bharat Tailor, \\ E-mail: sbapna.1@gmail.com \\ Copyright: () the author(s), publisher and licensee Medip Academy. This is an open-access article distributed under \\ the terms of the Creative Commons Attribution Non-Commercial License, which permits unrestricted non-commercial \\ use, distribution, and reproduction in any medium, provided the original work is properly cited.
}

\begin{abstract}
Background: MTP (is common procedure done by obstetrician under certain circumstances as per MTP rules and guideline, but it has certain complication and data about complication are not fully available. The aims of this study are to analyse various complication and causes of this complication following MTP presenting at our hospital.

Methods: This study was conducted in 100 patients coming to Pannadhay Rajkiya Mahila Chikitsalaya, RNT Medical college, Udaipur attending OPD (including emergency OPD) and IPD during August and September 2019 after MTP. This Study also included maternal mortality among all women participated in the study.

Results: A total of 100 cases included in study attended OPD (including emergency OPD) and IPD during study period. All cases were eligible for inclusion in the study. Medical method of abortion (MMA) was the most common method of termination of pregnancy adopted by patient. Prolonged bleeding, anaemia and Incomplete abortion was the common complication related to MTP and manual vacuum aspiration was done in majority of cases to manage incomplete abortion in our hospital setting.

Conclusions: The high rate of MTP related morbidity is due to induced abortion continue to be done at inappropriate places using inappropriate methods by person not eligible to do so.
\end{abstract}

Keywords: Abortion, First trimester medical termination of pregnancy, Medical method of abortion

\section{INTRODUCTION}

MTP is common procedure done by trained medical professionals under certain circumstances as per MTP rules and guideline. But it has certain complication and data about complication are not fully available. According to the first national study of the incidence of abortion and unintended pregnancy in India, an estimated 15.6 million abortions were performed in the country in 2015.

This translates to an abortion rate of 47 per 1,000 women aged 15-49, which is similar to the abortion rate in neighbouring South Asian countries. The study published today in "The Lancet Global Health" was conducted jointly by researchers at the International Institute for Population Sciences (IIPS), Mumbai; the population council, New Delhi; and the New York based Guttmacher Institute. It also found that the vast majority of abortions $(81 \%)$ were achieved using medication abortion (which, in India, is commonly referred to as medical methods of abortion, or MMA) that was obtained either from a health facility or another source. Fourteen percent of abortions were performed surgically in health facilities, and the remaining $5 \%$ of abortions were performed outside of health facilities using other, typically unsafe, methods. ${ }^{1}$ Medical termination of pregnancy act - The Indian parliament passed the medical termination of pregnancy (MTP) Act in 1971 with the goal of regulating and ensuring access to safe abortion. ${ }^{2}$

Who can perform - only registered allopathic medical practitioners. At place - at certified abortion facilities to perform abortions. 


\section{Uterine evacuation methods}

\section{For first trimester termination}

A. Vacuum aspiration

- Manual vacuum aspiration (MVA) - up to 12 weeks of pregnancy
- Electric vacuum aspiration (EVA) - up to 12 weeks of pregnancy.

B. Medical methods of abortion (MMA-by mifepristone and misoprostol) - up to seven weeks of gestation.

Table 1: Protocols for mifepristone and misoprostol.

\begin{tabular}{|c|c|}
\hline Day & Drugs used \\
\hline Day 1: mifepristone administration & 200 mg mifepristone oral; anti D $50 \mathrm{mcg}$, if Rh negative, \\
\hline Day 3: misoprostol administration & $\begin{array}{l}\text { Up to } 7 \text { weeks; } 400 \mathrm{mcg} \text { misoprostol (two tablets of } 200 \mathrm{mcg} \text { each) } \\
\text { sublingual/buccal/vaginal/oral "or" } 7-9 \text { weeks: } 800 \mathrm{mcg} \text { sublingual/ } \\
\text { buccal/vaginal. } \\
\text { In addition } \\
\text { - Analgesics (Ibuprofen) } \\
\text { - Antiemetic } \\
\text { - Offer contraception. }\end{array}$ \\
\hline Within day 15 : follow-up day & $\begin{array}{l}\text { - } \quad \text { Confirm and ensure completion of procedure. } \\
\text { - Offer contraception, if not already done so. }\end{array}$ \\
\hline
\end{tabular}

For second trimester termination methods

A. Medical methods

- Mifepristone and misoprostol regime

- Misoprostol alone regime

- Extra amniotic ethacridine lactate instillation supplemented by oxytocin

- Mechanical methods supplemented by oxytocic.

B. Surgical methods

- Dilatation and evacuation (D and E) (up to 15 weeks of gestational age)

- Hysterotomy.

\section{Indications}

In order to save the life of the pregnant woman,

- In order to prevent grave injury to the physical and mental health of the pregnant woman

- In view of the substantial risk that if the child was born it would suffer from such physical or mental abnormalities as to be seriously handicapped

- As the pregnancy is alleged by pregnant woman to have been caused by rape

- As the pregnancy has occurred as a result of failure of any contraceptive device or methods used by married woman or her husband for the purpose of limiting the number of children.

Note: Account may be taken of the pregnant woman's actual or reasonably foreseeable environment in determining whether the continuance of her pregnancy would involve a grave injury to her physical or mental health.

\section{Mandatory documentation}

- Form C: consent form

- $\quad$ Form I (RMP opinion form): RMP shall certify this form within three hours from the termination of pregnancy

- Form II (monthly reporting form) head of the hospital or owner of the place shall send a monthly statement of cases to the CMO of the district in this form

- Form III (admission register): an approved site shall maintain case records in Form III. This register is kept for a period of five years from the date of last entry.

All the above forms are to be filled for both surgical as well as medical methods of abortion.

\section{Consent}

In case of a woman more than 18 years only the consent of the woman is required to terminate pregnancy.Consent for the abortion is not required from the woman's husband or from other family members. In case of a minor (less than 18 years) or a mentally ill person, consent of a guardian is required. (Guardian means a caretaker willing to be responsible for the woman). 


\section{Gestational age}

The act allows an unintended pregnancy to be terminated up to 20 weeks' gestation; however, if the pregnancy is beyond twelve weeks, a second doctor's approval is required.

In 2010, the national training and service delivery guidelines of comprehensive abortion care were issued and included both surgical and medical guidelines. These guidelines mention that medical abortion with mifepristone and misoprostol may be provided up to 63 days' (nine weeks) gestation.,

\section{Prophylactic antibiotics for vacuum aspiration and dilatation and evacuation}

Prophylactic antibiotic regimens - doxycycline $200 \mathrm{mg}$ orally within 1 hour before procedure, American College of obstetricians and gynecologists (ACOG, 2018). In study hospital setting authors uses prophylactic antibiotic for all patient.

\section{Prophylactic antibiotics for medical abortion}

The American College of obstetricians and gynecologists (2014), the Society of Family Planning (Achilles and Reeves, 2011), the Royal College of obstetricians and gynecologists (2015) and the World Health Organization (WHO, 2014) do not recommend routine antibiotic use prior to medical abortion. In study hospital, antibiotic not used for MMA as per protocol.

According to the WHO clinical management guidelines, the first step in MVA should be to assess the woman's need for pain control and administer it as necessary. 5 Pain medication was given to all women undergoing Vacuum Aspiration. Non-steroidal anti-inflammatory drugs (NSAIDs) are recommended either prophylactically or at the time cramping begins.

In some cases, if suspected of GTD or any other pathology, specimen sent for histopathological examination.

Although MTP act is very liberal and patient friendly than also patient goes to untrained unrecognized-sector providers, including chemists and other vendors. ${ }^{6,7}$

Unsafe abortion is 'a procedure for terminating an unwanted pregnancy either by persons lacking the necessary skills or in an environment lacking the minimal medical standards, or both'.8 Of note 'unsafe' is not a synonym for 'illegal' or 'clandestine'. For example, legal abortions may be unsafe because of poorly trained clinicians, inadequate facilities, or both.

\section{Complications related to MTP includes}

- $\quad$ PID
- Anaemia

- Incomplete abortion

- Injury to genital tract (including perforation)

- Septic shock

- Hypovolemic shock.

Bleeding is generally a part of the normal course of an abortion. Only heavy bleeding (>12 hour) or longstanding bleeding (21 days) was included in bleeding complication. Some cases of prolonged bleeding cause severe anaemia $(<7 \mathrm{gm} / \mathrm{dl})$ and these patients need hospitalization for transfusion of blood and blood component.

Infection related to MTP are usually caused by ascending bacterial infection such as chlamydia, gonorrhoeal, mycoplasma and bacterial vaginosis (BV) from the lower genital tract via cervix to uterus. Infection of fallopian tube may cause infertility in future. Usually these patients come with bleeding, offensive vaginal discharge, lower abdominal pains and fever. In severe cases patient may come in shock also.

Maternal mortality is a key indicator of women's health and social status, and levels in India are unacceptably high. ${ }^{9}$ The maternal mortality ratio (MMR) for India is 130/100,000 live births (RGI-SRS: 2014-16) and unsafe abortions account for $8 \%$ of the MMR. Many of those who survive these procedures often suffer from chronic, debilitating diseases that have a bearing on the future reproductive health of the woman. By using safe abortion techniques as per rule, authors can decrease this mortality which is $8 \%$ of total MMR.

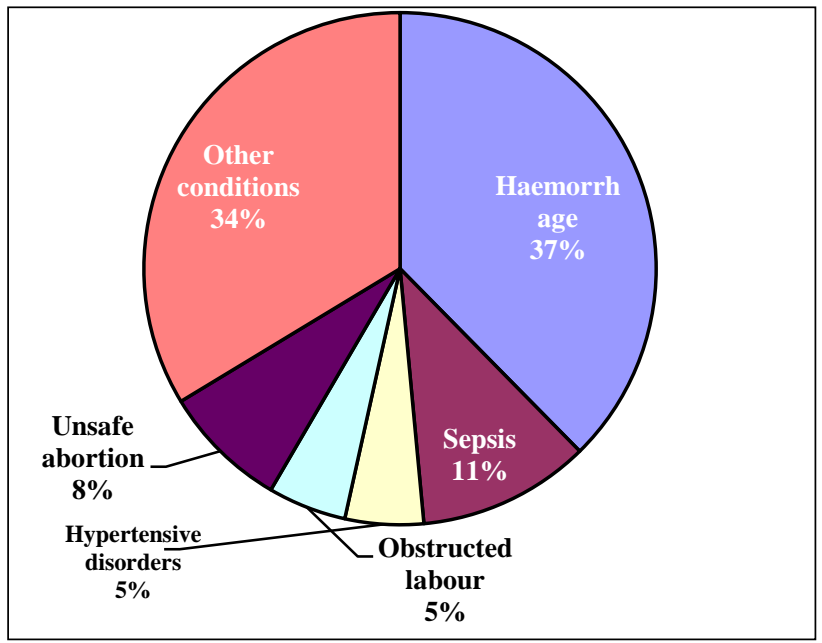

Figure 1: Major causes of maternal mortality.

Evidence from several community- and facility-base studies indicate that when women with an unwanted pregnancy, many women first attempt to terminate the pregnancy on their own, by using drugs purchased from a chemist without a prescription. ${ }^{10-12}$ Easy access to medicine from chemists has greatly contribute to an increase in unsafe abortion. ${ }^{13}$ 
Although there is little evidence on the safety or effectiveness of these (Ayurvedic, homeopathic and other allopathic drugs) drugs. Drug sellers lack knowledge about medical abortion, give wrong information to clients.

Data on the provision and quality of contraceptive counselling and services for abortion clients in India is limited. Studies from various settings in India also show that many women (49-96\%) want contraceptive methods after an abortion, although evidence suggests that many women receive inadequate or no post abortion contraceptive counselling or services. ${ }^{14-16}$ It is calculated that three out of four unsafe abortions may be eliminated if the need for family planning were fully met.

Incomplete abortion, post abortion sepsis, haemorrhage and genital trauma that reach hospital are the visible consequences of unsafe abortion, these serious complication typically indicate the use of an unsafe method. ${ }^{17}$ For every identified hospital case, there are many other women who have had an unsafe abortion, but who do not seek medical care, either because they do not have sufficiently worrying complications or because they fear abuse, ill-treatment or legal reprisals. ${ }^{18,19}$

The aim of this study was to analyse various complication and causes of this complication following MTP presenting at study hospital.

\section{METHODS}

This study was conducted in 100 patients (29 on OPD basis, 71 indoor) coming to Pannadhay Rajkiya Mahila Chikitsalaya, RNT Medical college, Udaipur attending OPD (including emergency OPD) and IPD during August and September 2019 after MTP. This Study also included maternal mortality among all women participated in the study.

During the study period abortion records were collected prospectively. Data collected included the number of previous induced and spontaneous abortions, parity, length of current pregnancy, results of bacterial screening, prescribed antibiotic treatment, and the chosen abortion method. Women were followed through the patient records system to determine the rate of complications. All patients who had a visit with a doctor at the gynecological clinic within 30 days after the abortion were included. Review of patient records and entered into the spreadsheet as an infection, bleeding, incomplete abortion, or other.

\section{RESULTS}

During the period of study, there were a total of 100 cases of complication of MTP included in study. All these patients were interviewed for the study.
Table 2 shows - out of these total patients 55 patient took MMA without any prescription of legal practitioner, 24 patients took MMA from recognized/ trained medical professional, 12 patients underwent surgical type of MTP method, and 9 patients took unknown medicine / not giving history/lying/others.

Table 2: Method of termination of pregnancy.

\begin{tabular}{|ll|}
\hline Method of termination of pregnancy & Percentage \\
\hline $\begin{array}{l}\text { Medical method of abortion without } \\
\text { prescription }\end{array}$ & $55 \%$ \\
\hline $\begin{array}{l}\text { Medical method of abortion with } \\
\text { prescription }\end{array}$ & $24 \%$ \\
\hline $\begin{array}{l}\text { Surgical method (MVA, S and E, D and } \\
\text { C) }\end{array}$ & $12 \%$ \\
\hline $\begin{array}{l}\text { Unknown/ not giving history/lying/ } \\
\text { others }\end{array}$ & $9 \%$ \\
\hline
\end{tabular}

Table 3: Patient complaints.

\begin{tabular}{|ll|}
\hline Patient complaints & Percentage \\
\hline Bleeding PV & $86 \%$ \\
\hline Pain abdomen & $12 \%$ \\
\hline Fever & $4 \%$ \\
\hline Foul smelling discharge & $4 \%$ \\
\hline
\end{tabular}

Table 3 shows - a total $86 \%$ patient had complaint of bleeding per vaginum, $12 \%$ pain abdomen, $4 \%$ fever, and $4 \%$ foul smelling discharge.

Table 4: Post abortion complication.

\begin{tabular}{|ll|}
\hline Complication & Percentage \\
\hline Incomplete abortion & $91 \%$ \\
\hline Anaemia $(\mathrm{Hb}>7 \mathrm{gm} / \mathrm{dl}$ to $10 \mathrm{gm} / \mathrm{dl})$ & $80 \%$ \\
\hline $\begin{array}{l}\text { Severe anaemia }(\mathrm{Hb}<7 \text { or equal to } \\
\text { gm/dl) }\end{array}$ & $8 \%$ \\
\hline Infection & $5 \%$ \\
\hline $\begin{array}{l}\text { Injury to genital tract (i/c uterine } \\
\text { perforation or any) }\end{array}$ & $2 \%$ \\
\hline Septic shock & $0 \%$ \\
\hline Hypovolemic shock & $2 \%$ \\
\hline Other & $0 \%$ \\
\hline
\end{tabular}

Table 5: Various mode of management.

\begin{tabular}{|ll|}
\hline Management & Percentage \\
\hline Evacuation by MVA & $92 \%$ \\
\hline Managed by medical method & $8 \%$ \\
\hline Antibiotic oral & $86 \%$ \\
\hline Antibiotic intravenous & $14 \%$ \\
\hline Blood and blood products & $10 \%$ \\
\hline Inj. iron sucrose & $35 \%$ \\
\hline Intravenous fluid & $5 \%$ \\
\hline ICU admission & $2 \%$ \\
\hline
\end{tabular}


Table 4 shows - a total $91 \%$ patient had incomplete abortion (most common), 5\% infection, $2 \%$ had injury to genital tract, and $2 \%$ hypovolemic shock. Incomplete abortion is most common type of post abortion complication. $8 \%$ patient had haemoglobin level of $<7$ $\mathrm{gm} / \mathrm{dl}$, anaemia in these patients may be due to preexisting anemia or due to prolonged/excessive bleeding.

Table 5 shows - manual vacuum aspiration (MVA), a portable, nonelectric device for uterine evacuation, was used to manage $92 \%$ of women admitted with incomplete abortions. Sharp curettage was not done in any patient. $8 \%$ patient managed with medical management. All patient received analgesic for pain relief. $86 \%$ patient received oral antibiotic and in $14 \%$ authors need injectable antibiotic to manage post abortion complication like septicaemia. $10 \%$ women treated with blood and blood products. No any patient needs laparotomy/hysterectomy during study period. Maternal mortality due to unsafe abortion during study period is nil in this study cases.

\section{DISCUSSION}

During the period of study, there were a total of 100 cases of complication of MTP included in study. All these patients were interviewed for the study.

Similar studies by Adanu et al there have been three previous studies on abortion at the Korle-Bu teaching hospital which have studied the epidemiology and complications of induced abortions showed high rates of medical abortion with prescription. ${ }^{20}$ Ampofo and Lassey showed that the majority of women had undergone medical method of abortions (Table 1). ${ }^{21,22}$

Adanu et al had similar results, wherein they showed high rates of patient complications as bleeding per vaginal followed by pain abdomen and foul-smelling discharge. Ampofo and Lassey showed that the majority of women had undergone medical method of abortions had bleeding per vaginal and foul-smelling discharge (Table 2). ${ }^{20-22}$

Similarly, in a study by Carlsson et al the main finding after compiling the results was an increasing number of complications after medical abortions. ${ }^{23}$ Incomplete abortions were found to be the most common complication. Concerning medical abortions $>12$ weeks and surgical abortions, it has been difficult to discern whether there are any trends since the numbers of medical abortions $>12$ weeks and surgical abortions are low and the cases of complications are few.

The frequency of infections after induced abortions appeared to be equal or even lower among patients who had a bacterial infection upon screening and therefore did receive antibiotics. Despite bacterial screening, there were still patients who suffered from infectious complications (Table 3).

\section{CONCLUSION}

Nearly $79 \%$ patient of who came with MTP complication took medicines for termination of pregnancy and out of which $69 \%$ patient took medicine/pill without any prescription.

Majority of users of MTP purchase the medication from chemists or other informal vendors and receive limited or inaccurate information without counselling. Inappropriate use of MTP kit, unapproved drug, ineffective drug, taking approved drug incorrectly all these contribute to post abortion complication.

In this study authors conclude that females are taking medicine from shop or directly from quacks, without legal protocol, probably because they are getting medicine easily without prescription/identity, this can be minimized by proper IEC.

Funding: No funding sources

Conflict of interest: None declared

Ethical approval: The study was approved by the Institutional Ethics Committee

\section{REFERENCES}

1. National estimate abortion - India released. Guttmacher Institute, News Release, December 11, $2017 . \quad$ Available https://www.guttmacher.org/newsrelease/2017/national-estimate-abortion-indiareleased\#. Accessed 27 ${ }^{\text {th }}$ March 2020.

2. The Medical Termination of Pregnancy Act 1971. Act No. 34. Government of India. Available at: https://main.mohfw.gov.in/acts-rules-and-standardshealth-sector/acts/mtp-act-1971. Accessed $27^{\text {th }}$ March 2020.

3. Comprehensive Abortion Care Training and Service Delivery Guidelines, Ministry of Health and Family Welfare. New Delhi. Government of India, 2010. Available

at: https://nhm.gov.in/New_Updates_2018/NHM_Comp onents/RMNCHA/MH/Guidelines/CAC_Training_a nd_Service_Delivery_Guideline.pdf. Accessed $27^{\text {th }}$ March 2020.

4. Acharya R, Kalyanwala S. Knowledge, attitudes, and practices of certified providers of medical abortion: evidence from Bihar and Maharashtra, India. Int J Gynaecol Obstet. 2012;118(1 Suppl.):S40-S46.

5. Clinical practice handbook for safe abortion. World Health Organization; Chapter 2.3. Pain management. 2014:25.

Available

at: https://apps.who.int/iris/bitstream/handle/10665/627 04/WHO_FHE_MSM_94.1.pdf?sequence=1\&isAllo wed $=y$. Accessed $27^{\text {th }}$ March 2020.

6. Larsson PG, Platz-Christensen JJ, Thejls H, Forsum $\mathrm{U}$, Pahlson C. Incidence of pelvic inflammatory disease after first-trimester legal abortion in women with bacterial vaginosis after treatment with 
metronidazole: a double-blind, randomized study. Am J Obstet Gynecol. 1992;166(1 Pt 1):100-3.

7. Brian G, Bell FS, Stobberingh E, Goossens H, Pringle M. A systematic review and meta-analysis of the effects of antibiotic consumption on antibiotic resistance. BMC Infect Dis. 2014;14:13.

8. Boland R, Katzive L. Developments in laws on induced abortion: 1998-2007. Int Family Plan Perspect. 2008;34(3):110-20.

9. Singh S, Remez L, Ram U, Moore AM, Audam S. Barriers to safe motherhood in India. New York: Guttmacher Institute; 2009:1-35.

10. Kumar R, Zavier AF, Kalyanwala S, Jejeebhoy SJ. Unsuccessful prior attempts to terminate pregnancy among women seeking first trimester abortion at registered facilities in Bihar and Jharkhand, India. J Biosocial Sci. 2013;45(2):205-15.

11. Bhattacharya S, Mukherjee G, Mistri P, Pati S. Safe abortion-Still a neglected scenario: a study of septic abortions in a tertiary hospital of Rural India. Online J Health Allied Sci. 2010;9(2):1-4.

12. Sowmini CV. Delay in termination of pregnancy among unmarried adolescents and young women attending a tertiary hospital abortion clinic in Trivandrum, Kerala, India. Reprod Health Matters. 2013;21(41):243-50.

13. Sri BS, Ravindran TK. Medical abortion: understanding perspectives of rural and marginalized women from rural South India, Int J Gynaecol Obstet. 2012;118(1 Suppl.):S33-S39.

14. Banerjee S, Clark K, Warvadekar J. Results of a Government and NGO partnership for provision of safe abortion services in Uttarakhand, India. New Delhi: IPAS India; 2009.

15. Agarwal S, Chauhan LN, Modi DA. Changing trends in MTP at SSG hospital, Baroda-a retrospective study. J Indian Med Associat. 2007;105(3):130-2.
16. Banerjee SK, Andersen KL, Baird TL, Ganatra B, Batra S, Warvadekar J. Evaluation of a multipronged intervention to improve access to safe abortion care in two districts in Jharkhand. BMC Health Serv Res. 2014;14(1):227.

17. Grimes DA, Benson J, Singh S, Romero M, Ganatra B, Okonofua FE, Shah I. Unsafe abortion: the preventable pandemic. Lancet. 2006;368(9558):1908-019.

18. Juarez F, Cabigon J, Singh S, Hussain R. Incidence of induced abortions in the Philippines: current level and recent trends. Int Family Plan Perspect. 2005;31(3):140-9.

19. Singh S, Prada E, Mirembe F, Kiggundu C. The incidence of induced abortion in Uganda. Int Family Plan Perspect. 2005;31(4):183-91.

20. Adanu RMK, MNNtumy, E Tweneboah. Profile of women with abortion complications in Ghana. Trop Doctor. 2005;35:139-42.

21. Ampofo DA. 330 cases of abortion treated at Korle$\mathrm{Bu}$ Hospital: the epidemiological and medical characteristics. Ghana Med J. 1970;9(3):156-62.

22. Lassey AT. Complications of induced abortions and their preventions in Ghana. East Afr Med J. 1995;72:774-7.

23. Isabelle C, Breding K, Larsson PG. Complications related to induced abortion: a combined retrospective and longitudinal follow-up study. BMC Women's Health. 2018;18:158.

Cite this article as: Rastogi R, Tailor B. Prospective study of complications of first trimester medical termination of pregnancy at tertiary care center. Int $\mathbf{J}$ Reprod Contracept Obstet Gynecol 2020;9:2536-41. 